\title{
UNDERSTANDING SMART CITY: A SHAREABLE FRAMEWORK. THE CASE OF CHINA
}

\author{
Chengming Li, Xiaoli Liu, Zhaoxin Dai, and Pengda Wu \\ Chinese Academy of Surveying and Mapping, 100830 Beijing, China
}

KEY WORDS: Smart City, Sharable Framework, Spatiotemporal Data, Cloud Platform, Smart Weifang, China

\begin{abstract}
:
Smart City is a new concept that uses Information and Communication Technology (ICT) to promote the smartification of urban construction, planning and services. Currently, a number of countries and cities have conducted studies on Smart City, but they mostly focused on the conceptual connotations analysis and applications in specific domains, lacking a common, shareable and integrated framework understanding, which led to significant barriers among individual Smart City projects. By analyzing the framework connotations and application domains of Smart City, this paper proposed a common, shareable and integrated conceptual framework for smart city. Then based on this framework, a unified portal platform that is suitable for multiple domains, including the government, citizen and business, as well as common, custom and other application modes, is further proposed. Finally, Smart Weifang was implemented based on this platform. The application outcomes indicate that this common and shareable platform can effectively eliminate the data and technological barriers between different smart city systems, while also avoiding redundant financial investments. The investigation of the proposed framework and platform is of key significance to the unified construction of Smart City and the intensification of the hardware environment, thus representing a true achievement in the transition from "information island" to "information sharing and interconnection" for urban informatization.
\end{abstract}

\section{INTRODUCTION}

United Nations World Urbanization Prospects report that more than half of the global population currently live in cities, and it can be expected to reach $66 \%$ by 2050 (Dirks et al., 2009; United Nations, 2014). The accelerating rate of urbanization has been accompanied by numerous challenges for urban development, and a series "urban diseases" have become increasingly prominent, such as resource shortage, environmental pollution, traffic congestion, security threats (Victoria et al., 2018). On the other hand, the continuous development of ICT has led to the improvement in the application of urban informatization, enabling information technology to become an effective means for urban governance, which eventually gave rise to the concept of Smart City.

The term 'Smart City' appeared for the first time in the early 1990s, which in 1993, the then US President Bill Clinton proposed the information superhighway program and emphasized the concepts of technology, innovation and globalization in the urbanization process (Alawadhi et al, 2012; Chourabi et al., 2012). Since 2008, with the launch of IBM's Smarter Planet project, Smart City have attracted great attention, and studies on its conceptual research underwent rapid growth and development (Palmisano, 2008). Harrison et al. (2010) defined smart cities as intelligent cities with wide interconnections in infrastructure, Internet, society and businesses. Giffinger and Gudrun (2010) provided six major characteristics of Smart City: smart economy, smart people, smart governance, smart mobility, smart environment and smart living. As an alternative to the traditional planning model, a common definition for a Smart City is a new concept and mode to promote the intellectualization of urban planning, management and service by using ICT such as (IoT), cloud computing and geospatial information (Washburn et al., 2009; Su et al., 2011; Mitton et al., 2012; Belissent et al., 2010; Jin et al., 2013; Peris-Ortiz et al., 2016).

However, despite the large amount of research conducted by numerous countries and cities on Smart City, and has also achieved substantial progress, they mostly focused on the conceptual framework analysis and applications in specific domains (e.g. smart transportation), lacking a common, shareable and integrated framework understanding. A city is a giant complex system, in order to meet the ever-changing needs of its citizens, all systems within the city should communicate accurately with each other, and share and utilize each other's resources timely and rapidly (Javidroozi et al., 2014). Smart projects in specific domains usually with the characteristics of resources monopoly and mutual independence, which leads to the following issues: (1) Inability to guarantee the consistency of public data and spatial base for different smart projects in the same city. (2) Inability to guarantee the consistence of different smart projects implementation due to the different viewpoints of the project implementers or researchers. (3) Inability to achieve the sharing and integration of different smart systems or data in Smart City. (4) Inability to guarantee the balance among various stakeholders (government, public administration and company).

To address the above-mentioned issues, this paper proposes a common, shareable and integrated conceptual framework for Smart City based on the in-depth study on the connotations and applications of Smart City. Based on this framework, a unified portal platform that is suitable for multiple domains, including the government, citizen and business, as well as common, custom and other application modes, is further proposed. The research on this framework and platform has important implications for the unified construction of smart cities and the intensification of the hardware environment. It represents a true achievement in the transition from "information island" to "information sharing and interconnection" in urban informatization.

\section{LITERATURE REVIEW}

\subsection{Concepts of Smart City}

An understanding of the concepts of Smart City is of crucial significance in understanding its scope and content, and guiding 
the development of its framework. As a new model of urban development, Smart City have broad conceptual extensions. Although it has been studied by numerous researchers and institutions, various concepts have been given by stakeholders from several different standpoints (Yin et al., 2015). There has little research to perform the explicit classification of definitions on Smart City from different perspectives. Based on the comprehensive analysis of the conceptual connotations and applications of Smart City, this paper conducted and analyzed the definitions of Smart City from four aspects: software and hardware infrastructure, spatiotemporal data and analysis, cloud platform systems and applications.

Software and hardware infrastructure: In 2008, IBM defined Smart City as cities that can fully utilize the interconnections in physical infrastructure, IT infrastructure, social infrastructure and business infrastructure to produce collective intelligence. Hall et al. (2000) proposed that smart cities are cities that monitor and integrate all its critical infrastructure, and make use of connections with networks, decision-making algorithms to optimize resources and monitor target security. Schaffers et al. (2011) considered smart cities as a model of urban development that makes use of ubiquitous networking and modern information technology to improve the city's competitiveness, achieve sustainable urban development, and improve residents' quality of life. Li et al. (2011) argued that the concept of Smart City involves equipping sensors to the urban to form the IoT, and defined Smart City as the IoT + the Internet.

Spatiotemporal data and analysis: With the development of technologies such as cloud computing and mobile Internet, a massive amount of data is generated from urban operations in various domains, including transportation, urban administration and businesses. Thus, spatiotemporal data with time and location characteristics has become important assets for Smart City, playing an crucial role in the construction and development of new smart cities (Batty, 2013; Lim et al., 2018). Al-Hader et al. (2009) stressed that the sending and receiving of big data are the foundation for the functional framework needed to monitor and control intelligent network asset management. Hashem et al. (2016) proposed that spatiotemporal data can aid decision-makers in planning the flexible expansion of services and resources in Smart City. In addition, Yin et al. (2015) and Nuaimi et al. (2015) have also considered that Smart City can be seen as the fusion, correlation, mining and application between data and information, thus indirectly emphasizing the importance of big data technology for the construction of Smart City. Various information technologies, such as cloud computing, big data analytics, IoT and mobile computing, have been widely applied in the concept of Smart City.

Cloud platform system: Li (2014) argued that Smart City is supported by spatiotemporal information and are dependent on ICT, such as cloud computing and the IoT, in order to materialize human knowledge into various activities, forming intelligent themes that are independent or less dependent on humans, and the combination of themes can be optimized based on demand. Li et al. (2011) believed that the core of smart cities is to adopt a smarter approach involving new-generation information technologies centered on the IoT and cloud computing, in order to change how the government, enterprises and people interact with each other. This smart approach is actually an integrated system of multiple decision-making and service algorithms. Javidroozi et al. (2014) proposed that for a city to be smart, it is necessary to integrate its city systems in order to deliver efficient services with flexibility and in real- time. In addition, other researchers have also proposed that understanding the balance among people, technology and institutions is of utmost importance to the construction of smart cities (Ben Letaifa,2015; Colldahl, Frey, \&Kelemen, 2013; Nam $\&$ Pardo, 2011b). The definitions above of smart cities stress the importance of having a smart and common information platform system in the construction and application of smart cities.

Application domains: Based on the perspective of application domains, Giffinger et al. (2007) defined smart cities as including smart economy, smart people, smart governance, smart mobility, smart environment and smart living. Lazaroiu and Roscia (2012) stressed the environmental, energy and management perspectives, proposing that smart cities should include smart economy, smart governance, smart environment, smart energy and smart mobility. The European Commission (2012) defined smart cities as cities with applications in energy efficiency, renewable energy and green urban transportation. Washburn et al. (2010) believe that smart city makes use of computing technologies to ensure city administration, education, healthcare, public safety, transportation and utilities are smarter, better connected and more efficient.

\subsection{Practical Application of Smart Cities}

Based on the Internet of Things, Catarinucci et al. (2015) proposed novel smart healthcare systems for the automatic monitoring and tracking of patients and biomedical devices in hospitals and nursing institutions. Demirkan (2013) proposed a data-driven, mobile- and cloud-enabled smart healthcare system in order to provide low-cost, high-quality healthcare services, thereby lowering costs and risks. Baig and Gholamhosseini (2013) classified and compared more than 50 smart health monitoring systems, based on which they performed a review and analysis of the efficiency, clinical acceptability, strategies and recommendations of the health monitoring systems.

Stefansson et al. (2013) used the conceptual model of a smart transportation management (STM) system to analyze the impact of the factors included in the system on distribution activities, and the management issues involved. Debnath et al. (2014) proposed a comprehensive, practical and unified urban smart transport framework based on the smartness of the urban transport system. Khazaei et al. (2016) proposed a cloud-based smart transportation platform, consisting of the data, analytics and management layers, which can be directly applied by researchers, traffic engineers and planners. Ding et al. (2015) believed that a key aspect of developing smart cities is to achieve smart transportation, which would improve urban transportation efficiency, safety and environmental sustainability. Thus, they proposed a general framework that manages big trajectory data in a scalable manner, which can support a variety of applications in smart transportation. Benevolo et al. (2015) analyzed the role of modern ICT in the construction of smart mobility. Buhalis and Amaranggana (2014) adopted the perspective of smart urban development and conceptualized the framework for smart tourism by analyzing the features of the tourism destinations, tourists' demands and complaints for the tourism destination and so on. Li et al. (2017) believed that smart tourism is a support system for individual tourists within the context of information services and allencompassing technology. Maalsen et al. (2018) presented the importance of smart housing and suggested that smart housing is the intersection among the ever-changing housing market, the new sharing economies and smart cities. 


\subsection{Limitations of Existing Research}

Although extensive research has been conducted on smart cities, the following problems still exist: (1) Conceptual frameworks of smart cities still lack common understanding and definitions from multiple angles. (2) When faced with different user (the government, the public, enterprises etc.) demands in the construction of smart cities, the construction of smart projects in different domains within the city will not be uniform. This includes inconsistencies in baseline data standards, data spatiotemporal benchmark and public processing technology, as well as the widespread phenomenon of resource monopoly, causing serious obstacles to individual smart thematic systems, with poor shareability and integration among them. For a city to be smart, it is necessary to integrate all systems, and to achieve the mutual communication and fusion among the systems, thus sharing and utilizing one another in a timely, accurate and rapid manner (Yin et al., 2015; Javidroozi et al., 2014). To address the issues above, this paper proposes a new shareable and integrated conceptual framework and platform for smart cities, which can achieve the sharing and fusion of different smart domains in the city, as well as balance the demands of different stakeholders (government, citizens and businesses) and different levels of users.

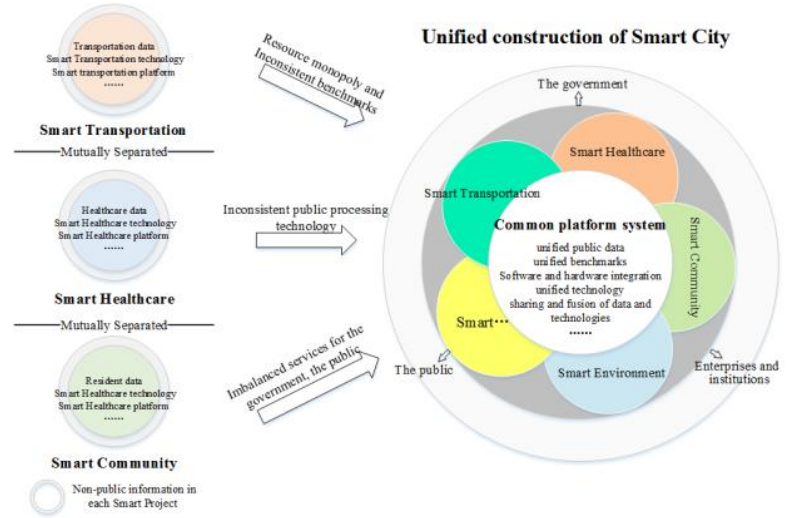

Figure 1. Schematic diagram of existing problems and strategies for smart cities

\section{SMART CITY FRAMEWORK MODEL}

\subsection{Overall Framework}

A comprehensive analysis was performed on the conceptual connotations and construction practices of smart cities worldwide. Although there were differences and distinctive characteristics in the understanding of connotations, framework construction and application domains, there were also commonalities in their system frameworks. This paper believes that smart cities are systems centered on information, communication and geospatial information technologies, with an orientation towards a series of key technologies and applications in the construction, operation, service and management of urban informatization. The key technologies include big data, intelligent sensing, next-generation communication networks, cloud computing, virtual reality, artificial intelligence, spatiotemporal information and other new technologies (Petrolo et al., 2015). The domain applications involve various aspects of government, civil and commercial affairs in urban land, planning, public security, environmental protection, transportation, energy, agriculture, hygiene, quality inspection, population, education, tourism, business etc., which are crucial technological pathways for the comprehensive and coordinated development of cities through integrated operations and information technology (Nam \& Pardo, 2011).

Based on which, this paper proposes a common, shareable and integrated conceptual (systems) framework for smart cities, as shown in Figure 2. It includes the sensor layer, network layer, computing and storage facility layer, public database layer, public information platform layer, smart applications layer and user layer, as well as the institutional security assurance system and policy standards assurance system.

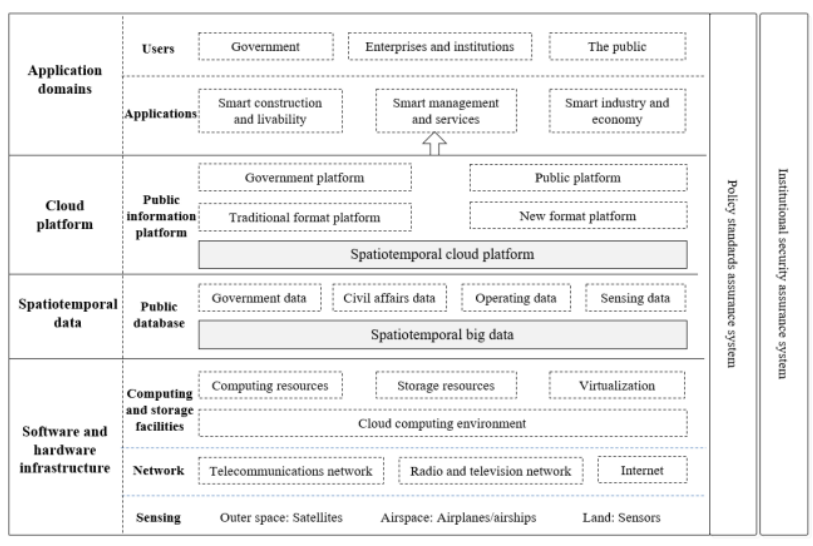

Figure 2. Smart city conceptual framework

The sensor layer can achieve the integrated data sensing of urban airspace, outer space and land, thus representing one of the key features distinguishing smart cities from the urban informatized construction in the past. The network layer can achieve the transmission of various types of information and is a core infrastructure of smart city construction. Computing and storage facilities refer to cloud computing environment facilities for the secure and efficient computing and storage of acquired data and information. The three layers above are known collectively as software and hardware infrastructure.

The public database is the data foundation for the unified construction of smart cities, providing a unified data base and benchmark for sharing and fusion in smart cities. This paper divides it into government data, civil affairs data, commercial operations data and various types of intelligent sensing data. This layer corresponds to spatiotemporal big data.

The public information platform mainly transforms spatiotemporal big data, infrastructure and other contents into information services and resources that can be shared and exchanged. These information services and resources are publicly available to the government, the public and businesses, thus building a common platform that supports the integration and aggregation of different resources and the open sharing of services. This layer corresponds to the cloud platform.

The applications layer provides applications services to the three domains of government, civil and commercial affairs. On the basis of the various services provided by the public information platform, it performs the service extraction and encapsulation of domain-oriented applications, providing certain common services and technical support within the domains, and fully serving the different domain applications of smart cities. By directly selecting applications related to itself in the applications layer, the user layer can directly serve multiple 
domains, including the government, the public and businesses, as well as general, custom and other multi-level users. This forms the service terminals of the entire smart city and ensures the balance among different stakeholders. The two layers above together form the applications domain.

The smart city architecture proposed in this paper is of crucial significance to the unified construction of smart cities and the intensification of the hardware environment. It represents a true achievement of the transition from "information island" to "information sharing and interconnection" in urban informatization. More specifically, the key to ensuring the sharing and fusion of individual systems within smart cities in order to achieve their unified construction lies with the construction of databases and platforms, that is, the construction of spatiotemporal big data platforms in smart cities. Spatiotemporal big data platforms are key components of smart cities; they are both indispensable, foundational information resources, as well as vectors for other information sharing, exchange and coordination applications. It provides a spatiotemporal basis for other information in the fourdimensional environment composed of three-dimensional space and time, thus enabling the planning, layout, analysis and decision-making based on a unified spatiotemporal basis. This will be described in greater detail in Sections 3.2 and 3.3. In addition, the software and hardware infrastructure in the overall framework is similar to that of existing studies, which are relatively mature, hence these will not be covered in detail in this paper.

\subsection{Spatiotemporal Big Data}

Urban operating signs can be directly presented through data quantification. Many studies have shown that the collection, processing and mining of big data is an important part of smart city construction (Souza et al., 2016; Mehmood et al., 2017; Batty,2013; Kitchin, 2014; Zhang et al., 2014). Allam and Dhunny (2019) proposed that data and mining analysis can help decision-makers to formulate adequate and responsive policies, which can facilitate better urban governance. Yin et al. (2015) believed that data-centric technologies play a key role in the implementation of smart cities. By summarizing international studies on the need for spatiotemporal data in smart city construction, as well as taking into account and eliminating the data barriers between smart city systems, this paper defines the spatiotemporal big data of smart cities as having four major parts: resource aggregation, spatial processing, data engine and distributed management system. These form a complete system, from unified data acquisition, aggregation and consistency processing based on ICT and other technologies, to data management and mining analysis based on artificial intelligence methods, thus providing a powerful guarantee for the sharing and fusion of data resources and processing technologies among individual systems in smart cities.

Resource aggregation: The application of ICT in urban construction has made the acquisition of massive data resources possible. The basic data in this study includes basic spatiotemporal data (e.g. administrative divisions, geographic entities, toponyms etc.), common thematic data (e.g. population data, socioeconomic data etc.; this data is derived from the information sharing among different sectors), IoT real-time sensing data (e.g. ICT-based monitoring data, video information) and Internet online crawling data (e.g. Weibo information), thereby forming spatiotemporal data resources that are integrated above and below ground, indoors and outdoors, and virtual and real.
Spatial processing: Urban big data is typically characterized by its massive volume, multiple sources and heterogeneity (Chen et al., 2014), with widespread problems such as false correlations and different measurement biases, which will lead to errors in the results of subsequent analyses (Fan et al., 2014). Therefore, prior to data analysis, different data types (traditional structured, semi-structured and unstructured data) need to undergo unified formatting, consistency processing and spatialization processing. Unified formatting mainly involves implementing lossless format conversion for different data, in order to establish spatiotemporal and topological relationships. Consistency processing mainly involves the consistency matching of historical and current data for similar data at different time points. More than $80 \%$ of data in the real world is related to geographic location; hence, spatialization processing is performed on all data through toponym feature extraction, spatial matching and data sequencing. The construction of this system can effectively resolve the issues of different resource data formats and basic data standards among individual smart city systems.

Data engine: Through this system, a full-space information model is established to achieve the integrated management of aboveground and belowground, indoor and outdoor, virtual and real, and real-time spatiotemporal big data. This overcomes the inefficiency of storing and accessing spatiotemporal big data stored in non-relational databases, making it difficult to meet real-time requirements under high concurrency and large data volumes, or to fully exert the performance advantage of nonrelational databases. It supports the cloud platform in helping users to call off-the-shelf data in spatiotemporal data online.

Distributed management and analysis: On the surface, big data is a series of static data stacking. However, it is, in essence, a dynamic process that involves performing complex analyses on the data in order to obtain a series of patterns. The true value of data can only be realized after it has undergone a certain degree of in-depth analysis (Al Nuaimi et al., 2015; Ibrahim et al., 2016). The spatial distribution patterns of the data are analyzed and mined based on neural network models, regression tree models, artificial intelligence models, cluster analysis and multiple correlation. On this basis, the prediction and deduction of urban state is achieved through spatiotemporal process simulation and other methods, in order to provide support for urban intelligent decision-making. The construction of this system can also achieve the storage and retrieval of big data, the effective integration of different database types, the real-time monitoring on the operating status of each storage node and the dynamic adjustment of load balancing.

The establishment of spatiotemporal big data can effectively resolve the issues of resource data monopoly, poor public data consistency and inadequate spatialization that are currently facing smart city construction. Thus, it guarantees a unified data level in the sharing and fusion of smart city systems.

\subsection{Cloud Platform}

Information sharing is an important basis for achieving the integrated development of smart cities. The public information platform is a media platform for the sharing and exchange of urban information. It performs the service-oriented packaging of resources in the computing and storage facility layer, public data resources, development interfaces, functional modules and mining knowledge, thus providing support services for the 
applications and user layers. Among the various key technologies of the public information platform, the cloud platform is a basic, supporting platform. It is based on cloud computing technology and is built in the cloud environment.

The cloud platform is based on the cloud center. Service systems and functions are developed and built according to the running network and hardware environment. The cloud center includes six parts: service and resource pool, service engine, toponym engine, business flow engine, knowledge engine and cloud management system. With computing and storage, data, interface, function and knowledge as its core, it forms a service resource pool, and establishes a service engine, toponym engine, business flow engine and knowledge engine. Together with the data engine of spatiotemporal big data, the cloud center conducts operation and maintenance management through the cloud management system, providing big data support and various services according to needs of different business applications. Among them, spatiotemporal big data is intimately connected with the spatiotemporal information cloud platform, whereby the data engine pushes the data service to the service resource pool of the spatiotemporal information cloud platform, and the two share the cloud computing environment.

More specifically, the service resource pool in this study mainly includes the data services provided by spatiotemporal data (e.g. location-based sensing information services), application programming interface services for data processing (e.g. simulation and deduction API), functional services (e.g. platform operation functions), computing and storage services (e.g. computing resource management services) and knowledge services that reflect the deep patterns in big data. The service engine is defined as a connection hub that implements the mutual communication and transformation of services in a flexible manner, thereby achieving the uploading, registration and publishing of other resources. The toponym engine can implement the online spatialization of thematic data, which serves as a bridge between spatial information and other information, thereby achieving the precise positioning of big data in the full-space information model. The business flow engine mainly presents the work in business processes using appropriate models based on logic and rules, and then implements calculations on the models, thus achieving the automatic processing of business processes. The knowledge engine implements online big data analysis, which provides big data analytics tools with different levels of capabilities to achieve the deep mining of data in order to acquire valuable knowledge. The cloud service system implements various functions through the visualization, modularization and servicification of different service resources and engines. It provides users with expressions and services through a friendly interactive interface, while also providing managers with management and monitoring through intelligent means.

The establishment of the cloud platform can effectively resolve the current problems of inconsistent construction implementation, inconsistent processing technologies and imbalanced services among stakeholders in smart cities. It also effectively intensifies the software and hardware environment, and guarantees a unified platform and technological layer for information sharing among different systems within smart cities.

\subsection{Application Modes}

The unified smart city system architecture and platform system proposed in this paper is able to meet the basic application needs and rapid construction of thematic systems required by government departments, enterprises and institutions, and the public. Unlike general application systems, the system architecture proposed here is designed for different users, providing multiple types of application modes, including direct applications, custom applications, standard services and inline call.

(1) Direct applications: These are mainly for ordinary users to call various service functions, load thematic information, and perform spatial statistical analyses and queries.

(2) Custom applications: These are mainly for custom users, who use a secondary development interface and combine it with their own special requirements to perform the encapsulation of personalized graphical interface, and the development and expansion of functions, in order to customize thematic application systems.

(3) Standard services: These are mainly for development users to implement map and geographic information network services, support the client in using other GIS software to develop thematic application systems, and perform the distributed call of service resources.

(4) Inline call: This is mainly for embedded users, providing network linking technology to support users in performing the embedded online call of other information services without making any changes in business operation systems that users have already put into use.

\section{APPLICATION IN CHINA'S SMART CITY CONSTRUCTION}

To verify the application outcome of the smart city system framework and platform system, the system framework and platform proposed in this paper were used as the spatiotemporal base for smart city construction. Smart city platform construction began in 2006, and by the end of 2017 , construction was under way in 334 prefecture-level cities and 511 county-level cities throughout China. At present, construction has been completed in 290 prefecture-level cities and 214 county-level cities, where the system is currently in use. This has benefited dozens of domains, including land, planning, transportation, real estate, public security, fire protection, hygiene and public services, playing an important role in socioeconomic development, industry and informatization. In this section, we will present a detailed discussion on a case study of smart city construction in Weifang City, Shandong Province, China.

Based on the smart city system framework and platform system proposed in this paper, we investigated and carried out the construction of Smart Weifang, where a citywide crossdepartmental, cross-system information resource sharing and exchange system was established.

\subsection{Construction of Spatiotemporal Data}

Based on the four data types proposed in this paper, different methods of data aggregation were studied and developed. Through resource aggregated, we ultimately achieved the aggregation of Weifang City4 big data resources with a data volume of nearly $100 \mathrm{~TB}$. This included 10 categories of basic geographic information data amounting to 50TB, 60 million thematic data from 22 industries and 49 municipal departments in Weifang City, 6 categories of 129 spatial planning data and 
10 types of real-time intelligent sensing data from more than 100,000 terminals, which provided a solid and rich data foundation for the construction of Smart Weifang.

In addition, based on the knowledge mining framework and knowledge engine for spatiotemporal big data, we implemented the discovery and identification of spatial distribution patterns, time series development patterns and attribute structural patterns for thematic data in Weifang city, as well as the deep mining of association relationship and causal relationship among multiple types of thematic data. This enhanced the government's scientific and precise decision-making, as well as its ability to carry out predictions, warnings and emergency responses.

\subsection{Construction and Application of Cloud Platform}

As a platform medium for providing spatiotemporal information services to different types of users, Smart Weifang constructed three types of platforms according to its different application targets, namely the general, specialized and public platforms, which concisely embody its service philosophy of "Intelligentization, Smartification, Knowledgization".

The general platform is mainly based on the cloud platform architecture proposed in this paper in its implementation of related functions. It mainly provides services for the integration of citywide spatiotemporal information, autonomization of cloud platform selection autonomy and knowledgization of big data mining. Based on the general module of the cloud platform the specialized platform is oriented towards Weifang City's work demands for the integration of multiple plans and management of natural resources. Thus, we expanded the relevant specialized data and implemented functional modules to build a specialized spatial planning platform and a specialized natural resource monitoring platform, in order to better serve the natural resource monitoring and spatial planning work in Weifang City. The public platform includes "Map World: Weifang" on computer terminals and "Weifang Map" on mobile terminals. In addition to providing various types of data services that are available to the public, it also publishes information on real estate registration, healthcare, police service, bike-sharing, bank branches and so on, thus truly achieving the provision of informatized services.

As of the end of 2017, the Smart Weifang system had aggregated, published and shared more than 900 service resources, nearly 300 graphic data resources and four categories of more than 20 knowledge results, as well as docking hundreds of third-party application systems.

\subsection{Evaluation of Application Outcomes}

With regards to information sharing, the construction of Smart Weifang has effectively eliminated the data and technological barriers between systems. Moreover, the construction of a common platform has significantly improved citywide crossdepartment and cross-system information sharing, thereby forming the coordinated advancement and integrated strategic leadership of smart city construction.

In terms of socioeconomic benefits, the construction of Smart Weifang has effectively prevented redundant financial investments, thus saving large sums of financial funds and producing good economic benefits. More specifically, at the data level, compared to the duplicate data purchases originally made by individual departments, the costs of buying large-scale topographic maps, electronic maps, toponyms, 3D models and other data covering only the $351 \mathrm{~km} 2$ of the Weifang City metropolitan area and the $640 \mathrm{~km} 2$ of the eight counties and cities resulted in annual savings of RMB 110 million. In terms of software and hardware infrastructure, this common platform allowed the individual departments to store large amounts of shared data in the cloud center. Compared to the original practice of each department purchasing individual software and hardware equipment for separate storage, this platform has effectively achieved hardware intensification and multiple usage, thus avoiding redundant financial investments and saving approximately RMB 18 million per year. As for the development of thematic services, traditional smart city platform construction, from data generation, procurement of basic software and hardware to system development, tend to have a research and development cycle of more than half a year, generally requiring 1-2 years. However, by adopting this access platform to directly perform secondary development and thematic domain application, the cycle can be shortened by $60-8$ months. Hence, it not only improves efficiency, but also reduces development costs by approximately RMB 15 million per year.

Based on the comparison with the indicators of original smart project construction, the common smart city framework proposed in this paper was highly innovative, strongly systemic and had significant socioeconomic benefits. Hence, it can provide a scientific basis to support urban scientific decisionmaking, rational planning, delicacy management and efficient operations. Professor Qin Qiming of Peking University, who is an expert in the field of geographic information, believes that the complete set of technologies and construction models developed in Smart Weifang has provided a solution to the construction of smart cities in China that can be replicated, promoted and implemented. In 2017, Smart Weifang passed the inspection by China's former State Bureau of Surveying and Mapping, and became the first pilot prefecture-level city to pass this inspection.

\section{CONCLUSION}

Smart cities are a new concept that uses next-generation information technology to promote the smartification of urban planning, construction, management and services. Currently, a number of countries and cities have conducted studies on smart cities, but these have mostly focused on analyzing the conceptual connotations of smart cities and practical applications in specific domains. Hence, there is a lack of studies on common, shareable and integrated systems, which has led to significant barriers between individual systems in smart cities. In view of current issues such as resource monopoly and serious barriers in smart city construction, this paper performed an in-depth analysis on the connotations and application domains of smart city frameworks and proposed a common, shareable and integrated conceptual framework for smart cities. Based on this framework, we further proposed a unified portal that is suitable for multiple domains, including the government, citizens and businesses, as well as general, custom and other application modes. This study has important implications for the unified construction of smart cities, the intensification of hardware environment and truly achieving the integration of smart city construction. Hence, it can provide theoretical support for the unified construction and application of smart cities. The main conclusions of this study are as follows: 
(1) Based on the in-depth analysis of the connotation analysis of smart cities by different researchers, we concluded that smart cities should be defined and understood from four key aspects: software and hardware infrastructure, spatiotemporal big data and processing, cloud platform system and application domains.

(2) A common, shareable and integrated system architecture for smart cities was proposed. The structure of this system is mainly composed of the software and hardware infrastructure layer, public database layer, cloud platform layer, smart applications layer and user layer.

(3) The study summarized the key technologies for smart city construction, centered on spatiotemporal big data and cloud platform, which will guarantee that information sharing among individual systems in smart cities will be unified at the data and technological levels.

(4) Based on the proposed common framework and platform, this study carried out the construction of Smart Weifang. The practical outcomes indicated that: In terms of information sharing, it can effectively eliminate the data and technological barriers between systems, which significantly improved citywide cross-department and cross-system information sharing, thereby forming the coordinated advancement and integrated strategic leadership of smart city construction. In terms of socioeconomic benefits, it effectively prevented redundant financial investments and saved large sums of financial funds. According to incomplete statistics, when compared to traditional smart city construction, Smart Weifang saved approximately RMB 150 million a year in expenses, hence provided good economic benefits.

This paper mainly investigated and designed a common framework and platform system for smart cities from the perspective of information sharing and integration, which is very useful for the Smart City unified construction. We have also described the framework architecture and certain key technologies. The specific implementation technologies and models were not discussed directly in the article. However, with the emergence of different structural data, the real-time updating of new processing techniques and methods will become especially crucial for the common platform. Hence, in future research, more emphasis will be placed on the design of intelligent technologies and upgrading of the platform system, in order to ensure the provision of long-term and effective support for the application and development of big data in smart cities.

\section{REFERENCES}

Alawadhi, S., Aldama-Nalda, A., Chourabi, H., Gil-Garcia, R., Leung, S., Mellouli, S., Nam, T. 2012. International Conference on Electronic Government, 7443:40-53.

Al-Hader, M., Rodzi, A., Sharif, A., Ahmad, N. 2009. Smart city components architecture. In: Proceedings of International Conference on Computational Intelligence, Modelling and Simulation, Brno, 93-97.

Allama, Z., Dhunny, Z., 2019. On big data, artificial intelligence and smart cities. Cities, 89:80-91.
Al, N., Al Neyadi, H., Mohamed, N., 2015. Applications of big data to smart cities. Journal of Internet Services and Applications, 6 (1): 1-15.

Baig, M. and Gholamhosseini, H., 2013. Smart Health Monitoring Systems: An Overview of Design and Modeling. Journal of Medical Systems, 37:9898.

Batty, M., 2013. Big data, smart cities and city planning. Dialogues in Human Geography, 3(3):274-279.

Belissent, J., 2010. Getting Clever About Smart Cities: New Opportunities Require New Business Models. Cambridge, Massachusetts, USA, 193.40.244.77.

Benevolo, C., Dameri, RP., D’Auria, B., 2015. Smart mobility in smart city. Empowering Organizations, 13-28.

Buhalis, D. and Amaranggana, A., 2014. Smart Tourism Destinations. Information and Communication Technologies in Tourism, 553-564.

Catarinucci, L., Donno, D., Mainetti, L., Palano, L., Patrono, L., Stefanizzi, M., Tarricone, L. 2015. An IoT-Aware Architecture for Smart Healthcare Systems. IEEE Internet of Things Journal, 2(6):515-526.

Chen, M., Mao, S., Liu, Y., 2014. Big data: a survey. Mobile Networks and Applications, 19 (2): 171-209

Chourabi, H., Nam, T., Walker, S., Gil-Garcia, J., Mellouli, S., Nahon, K., Pardo, T., Scholl, H. 2012. Understanding smart cities: An integrative framework. 45th Hawaii International conference on system sciences, 4-7: 22892297.

Debnath, A., Chin, H., Haque, M., Yuen, B. 2014. A methodological framework for benchmarking smart transport cities. Cities, 37:47-56.

Demirkan, H., 2013. A Smart Healthcare Systems Framework. IT Professional, 15(5):38-45.

Ding, Z., Yang, B., Chi, Y., Guo, L. 2016. Enabling Smart Transportation Systems: A Parallel Spatio-Temporal Database Approach. IEEE Transactions on Computers, 65(5):1377-1391.

Dirks, S., Keeling, M., 2009. A vision of smarter cities: how cities can lead the way into a prosperous and sustainable future. IBM Institute for Business Value.

European Smart Cities. Centre of Regional Science Vienna University of Technology; 2012. Available from: http://www.smart-cities.eu/model.html. 05/09/2012.

Fan, J., Han, F., Liu, H., 2014. Challenges of big data analysis. National Science Review, 1, 293-314.

Giffinger, R., Gudrun, H., 2010. Smart cities ranking: an effective instrument for the positioning of the cities? Architecture. City Environ, 4: 7-26.

Hall, R., 2000. The vision of a smart city. The 2nd International Life Extension Technology Workshop. Paris, France. 
Harrison, C., Eckman, B., Hamilton, R., Hartswick, P., Kalagnanam, J., Paraszczak, J., Williams, P. 2010. Foundations for smarter cities. IBM J Res Develop, 54: 116.

Hashem, I., Chang, V., Anuar, N., Adewole, K., Yaqoob, I., Gani, A., Ahmed, E., Chiroma, H. 2016. The role of big data in smart city. International Journal of Information Management, 36(5):748-758.

Javidroozi, V., Shah, H., Amini, A., Cole, A. 2014. Smart city as an integrated enterprise: a business process centric framework addressing challenges in systems integration. In Proceedings of 3rd International Conference on Smart Systems, Devices and Technologies, Paris, 55-59.

Jin, J., Gubbi, J., Marusic, S. Palaniswami, M. 2013. An Information Framework for Creating a Smart City Through Internet of Things. IEEE Internet of Things Journal, 1(2):112-121

Khazaei, H., Zareian, S., Veleda, R., Litoiu, M. 2015. Sipresk: A Big Data Analytic Platform for Smart Transportation. SmartCity 360, 419-430.

Kitchin, R., 2014. The real-time city? Big data and smart urbanism. GeoJournal, 79: 1-14.

Lazaroiu, G., Roscia, M., 2012. Definition methodology for the smart cities model. Energy, 47: 326-332.

Li, Y., Hu, C., Huang, C., Duan, L 2017. The concept of smart tourism in the context of tourism information services. Tourism Management, 58:293-300.

Lim, C., Kim, K-J., Maglio, P., 2018. Smart cities with big data: Reference models, challenges, and considerations. Cities, 82:86-99.

Li, C., 2014. What is a smart city? Land \& Resources Herald, 09:49-50.

Li, D., Shao, Z., Yang, X., 2011. Theory and Practice from Digital City to Smart City. Geospatial Information, 9(6):15 .

Maalsen, S., 2019. Smart housing: the political and market responses of the intersections between housing, new sharing economies and smart cities. Cities, 84:1-7.

Mehmood, R., Meriton, R., Graham, G., Hennelly, P., Kumar, M. 2017. Exploring the influence of big data on city transport operations: A Markovian approach. International Journal of Operations \& Production Management, 37: 75104.

Mitton, N., Papavassiliou, S., Puliafito, A., Trivedi, K. 2012. Combining Cloud and sensors in a smart city environment. EURASIP J Wirel Commun Netw, 2012: 1-10.

Nam, T., Pardo, T., 2011. Smart city as urban innovation: Focusing on management, policy, and context. In: Proceedings of 5th International Conference on Theory and Practice of Electronic Governance. New York: ACM, 185-194.
Nuaiim, E., Neyadi, H., Mohamed, N., Al-Jaroodi, J. 2015. Applications of big data to smart cities. Journal of Internet Services and Applications, 6:25.

Palmisano, S. 2008. A smarter planet: the next leadership agenda. IBM. November .

Peris-Ortiz, M., Bennett, D., Yábar, D., 2016. Sustainable Smart Cities: Creating Spaces for Technological, Social and Business Development. Springer. ISBN 9783319408958

Petrolo, R., Loscrì, V., \& Mitton, N., 2015. Towards a smart city based on cloud of things, a survey on the smart city vision and paradigms. Transactions on Emerging Telecommunications Technologies, 28, e2931.

Schaffers, H., Komninos, N., Pallot, M., Trousse, B., Nilsson, M., Oliveira, A. 2011. Smart cities and the future Internet: Towards cooperation frameworks for Innovation. International Journal Domingue, The Future Internet, Springer, 431-446.

Souza, A., Figueredo, M., Cacho, N., Araújo, D., Prolo, C. 2016. Using big data and real-time analytics to support smart city initiatives. IFAC-PapersOnline, 49:257-263.

Stefansson, G. and Lumsden, K., 2013. Performance issues of Smart Transportation Management systems. International Journal of Productivity and Performance Management, 58(1):55-70.

Su, K., Li, J., Fu, H., 2011. Smart city and the applications. In: Proceedings of IEEE International Conference on Electronics, Communications and Control (ICECC), Ningbo, 1028-1031.

United Nations, Department of Economic and Social Affairs. 2014. World urbanization prospects: the 2014 revision. New York.

Victoria, F., José, M., Rudolf, G., 2018. Smart City implementation and discourses: An integrated conceptual model. The case of Vienna. Cities, 78:4-16.

Washburn, D., Sindhu, U., Balaouras, S, Dines, R. 2009. Helping CIOs understand 'smart city' initiatives. Growth, 17.

Yin, C., Xiong, Z., Chen, H., Wang, J., Cooper, D., David, B. 2015. A literature survey on smart cities. Science China Information Sciences, 58:10012(18).

Zhang, D., Song, T., Li, J., Liu, Q. 2014. A linked data-based framework for personalized services information retrieval in smart city. In: Proceedings of Workshops on Web Information Systems Engineering. Berlin/Heidelberg: Springer, 461-473.

Smith, J., 2000. Remote sensing to predict volcano outbursts. Int. Arch. Photogramm. Remote Sens. Spatial Inf. Sci., XXVII-B1, 456-469. 